\title{
A260 to A230 Ratio
}

National Cancer Institute

\section{Source}

National Cancer Institute. A260 to A230 Ratio. NCI Thesaurus. Code C139281.

An assessment of nucleic acid purity that is measured by determining the ratio of light absorbance of the nucleic acid sample at $260 \mathrm{~nm}$ and $230 \mathrm{~nm}$ respectively. 